\title{
The Phenomenon of Teenage Pregnancy in the Philippines
}

\author{
Jordan Tovera Salvador, PhD, RN \\ Ben Ryan Jucay Sauce, MN, RN, RM \\ Marc Oneel Castillo Alvarez, MAN, RN, RM \\ Ahrjaynes Balanag Rosario, MAN, RN \\ University of Dammam, Kingdom of Saudi Arabia
}

doi: 10.19044/esj.2016.v12n32p173 URL:http://dx.doi.org/10.19044/esj.2016.v12n32p173

\begin{abstract}
Teenage Pregnancy had been a worldwide issue, and has raised large numbers of campaigns and awareness to lessen its occurrence. The total number of this phenomenon is increasing each year. Philippines is one of the Asian countries which shares similar situation. In a study conducted by the National Demographic and Health Survey in 2013, one out of every young Filipino women age 15 to 19 is already a mother or pregnant with a first child. Therefore, the government in partnership with the different nongovernment agencies should exert efforts in resolving this issue. Teenage Pregnancies are often associated with social development issues such as lack of sufficient education and poverty. This often results to single parenthood which catalyzes conditions that renders the mothers to become irresponsible. Hence, it conveys a social stigma in various countries and cultures. This study would like to focus on exploring the lived experiences of Filipino teenage mothers in their pre and post-natal stage on how they prepare and accept their new roles as mothers. The gathered data from the methods were analyzed and interpreted according to qualitative content analysis. As a result, this generated emergent themes which depicted the experiences of the participants.
\end{abstract}

Keywords: Motherhood, Phenomenological Study, Qualitative Research, Teenage Pregnancy

\section{Introduction}

Teenage pregnancy has been a worldwide issue that needs to be confronted to mitigate the problems of maternal adolescent childbearing, especially in the third world countries. In fact, it has emerged to be one of the major public health problems in South Asia (Raj et al., 2010) and in 
Western Europe (Seamarck, 2001). It is reported in India that adolescent pregnancy is one of the serious health threat for women aged 15-19 years old (Patra, 2016). In Nigeria, the ratio of teenage mothers to women in their 20s who actually die during pregancy and childbirth is 5:1. In addition, they likely have more higher mortality rates for infants (Amoran, 2012).

Consequently, social analysts and researchers enumerated some of the reason why pregnacies among adolescents have been increasing in spite of interventions from government health agencies and NGOs. Thus, the reasons varies from socio-economic status (Dulita, Nalika, Upul, Crishantha \& De Alwis, 2013), lack of education (Eloundou-Enyegue, 2004), teenagers' initiation to sexual activity (Grace, Ihuoma \& Temitope, 2013), family history of teenage births (Wall-Wieler, Ross \& Nickel, 2016), etc. The incidence of mortality in teenage pregnacies and adverse birth outcomes is increasing every year due to immature pre-natal care, socio-economical challenges, and inadequte weight gained during pregnancy (Xi-Kuan, Shi Wu, Flemming Demissie \& Rhoads, 2007).

However, the Philippines have the same predicament regarding teenage pregnancy. Due to the official ranking of the United Nation Population Fund Agency in 2012, the number of teenage pregnancies, aged 10-19 years old, have increased to $70 \%$ over the last ten years. As a result, this has imposed a huge problem towards the achievement of Millenium Development Goals that puts the country in red alert (Philippine News Agency, 2012). Moreover, 14\% of the teenage girls in the age bracket of 1519 were reported for the first time to be already mothers or have had several children in the 2014 survey of Young Adult Fertility and Sexuality as compared to the 8\% of the 2002 survey (Au-Yeung, 2014). Among the reasons identified, the major causes of teenage pregnancies are limited access to sexual education and sexual health services. This is contrary to the church teachings' alternative methods of family planning. New technology is also considered as one of the major culprits to the increased number of teenage pregnancy cases. Occassionally, teenagers get hooked to different social networking sites such as Facebook, Online Dating, Instagram, etc. using their smartphones, notebooks and tablets. Due to easy access to new technology and the curiousity of teenagers to engage in sexual activities without appropriate knowledge about family planning and contraceptions, it often ends up with unplanned pregnancy. The big question is: Are they prepared for the role of a mother despite their young ages? How far can teenagers go to get rid of the unwanted pregnancy? Is abortion an option?

\section{Methodology}

The primary objective of this qualitative phenomenological research is to explore and understand the lived experiences of mothers in their teenage 
years. Phenomenology is the study of phenomena (Salvador, 2016). Thus, it states that each situation or experience can only be experienced by a single person who has gained new perceptions and insights (Crotty, 1997). The insights from this study may be beneficial to others and is considered as the primary goal of research (Bryman, 2012). Moreover, phenomenological inquiry is grounded on exploring and understanding the lived experiences of human beings. This can be achieved by figuring-out the meaning of the experiences and human being's lived experiences' essences (Creswell, 2012).

This phenomenological study was anchored on Sister Callista Roy's (1980) - Adaptation Theory. This theory 'defines adaptation as the process by which an individual or group makes conscious choices to cope with his or her situation. Adaptive responses increase people's ability to cope and to achieve their goals including survival, growth, mastery of their lives, and personal and environmental transformation'. However, Roy's adaptation theory stated that there are four distinctive modes: physiologic (basic needs including food, sleep, air, water, and the necessities of protecting the body); self-concept (beliefs and feelings about self); role identity/function (personal perspective to the social world); and interdependence (personal relationship towards the whole organization).

Therefore, a person is an open adaptive system who uses coping skills to deal with stressors. In line with the study, the 'person' represents the teenage mothers. Roy sees the environment as "all conditions, circumstances, and influences that surround and affect the development and behavior of the person" (Andrews \& Roy, 1991). Environment then may sum up the challenges of the participants in facing life with pregnancy and motherhood. However, Roy's goal for nursing is "the promotion of adaptation in each of the four modes, thereby contributing to the person's health, quality of life, and dying with dignity" (Roy, 1980).

The participants of the study were sixteen (16) teenage mothers aged 13-19 years old who are currently residing in the capital of the Philippines. Selection of participants was obtained through purposive sampling. The inclusion criteria for this study include: informed consent signed by both participants and at least one of the biological/legal foster parents; age bracket of 13-18 years old; willingness to share their lived experiences; and their commitment to attend follow-up dialogues.

Consequently, semi-stuctured in-depth interviews were facilitated as the main research instrumentation in gathering the data. However, participants were given the option if they wish to be withdrawn anytime to preserve the principle of automony and confidentiality. Observations, use of field notes (personal, transcript and analytical), audio-visual recordings, and 
qualitative documents were also used to supplement the data collection process.

Interviews were transcribed verbatim in preparation for the data analysis. Coding techniques and pseudonames were utilized to maintain confidentiality. In keeping with the intended methodology, qualitative content analysis inspired by Collaizi (1978) was utilized to explicate the essence of the phenomenon (see figure 1).

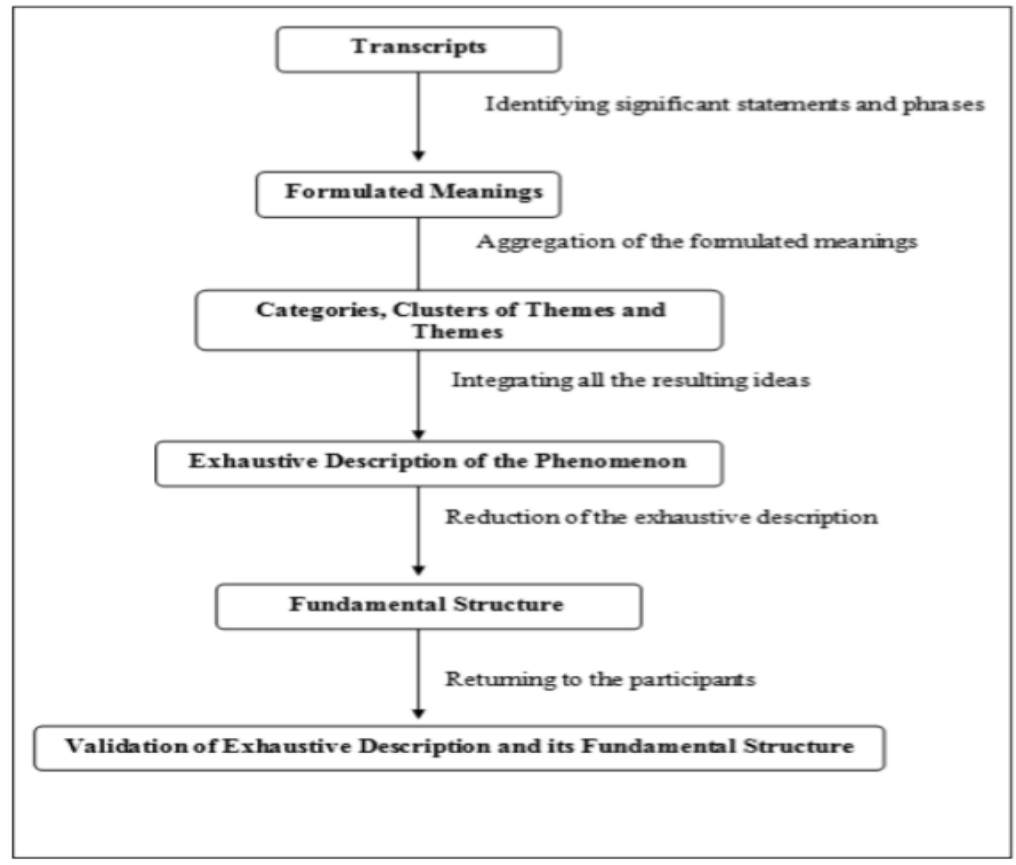

Figure 1. Summary of Collaizi’s Strategy for Phenomenological Data Analysis (Abu Sosha, 2012)

\section{Results}

Upon utilizing the intended data analysis approach, 4 emergent themes were generated: 'Period of Adolescence', 'Bearing a Child', 'The Mother and Child', and 'Building New Dreams'. Additionally, emergent themes will be discussed in relation to the lived experiences of the participants supported through the review of literature.

\section{Period of Adolescence}

World Health Organization (2014) described the adolescence stage as ' a period of development and growth which happens after childhood and before adulthood from ages 10 to 19'. Next to infancy, it is characterized by a demanding evolution in the genes which is outlined by an immense process in growth and changes. With the dawn of puberty marking the transition 
from childhood to adolescence, many biological stages rise up from this growth and development. To better understand this emergent theme, four theme clusters were drawn to help readers understand awakening as a theme.

The first theme cluster is the 'metamorpohosis of a girl to a lady'. The process of adolescence assembles a child for adulthood which can simply be noticed in the physical and sexual progression. However, these living changes takes place in these developmental years as manifested by the increase in height, more structured muscles and bones, and a more developed secondary sexual traits. Between the ages of eight to thirteen, girls start to develop breast. Their hips widen and hair starts to grow in the genital region. Growth spurts is evident as seen in their sudden growth in height. Also, the outset of menstruation or menarche symbolizes that a girl is matured sexually. However, this usually occurs between the age of nine and fourteen years, and it differs on particular basis. One participant mentioned:

"When I first got my period, they told me I am already a grown-up. I have seen changes in my body. But, I don't know how to be a real grown-up..."

Teenage dilemma is the second sub-theme cluster which emerges from this emergent theme. Teenagers feel disturbed, especially with what they see and hear in the surroundings they are growing. Many are distracted about their uniqueness, potentials, and direction. The fifth stage of Erickson's Psychological Stage happens during teenage years. This is also the point where the personal identity of a person's life is established. At this stage, the process of exploration and eagerness to know a lot of things are distinguished. Sense of self is actually being refined. However, a lot of questions are swirling on the teenagers' minds like "Who am I?" and "What do I want with my life?" These are clear evidences that at this point in time, teenagers attempt to do things that would gratify them. Until such a time, they will realize that they fit in. Confusion is exemplary during this stage. Peers perform a significant role in the life of minors. Thus, a verbalization from a participant states: I am confused of what is really right from wrong. I have seen other people doing bad things as if it is right. I am really confused...'

The third theme cluster derived from this theme is 'exploring the curious mind'. The adolescents, at this point in time, are born into a society equipped with technology. They are provided massive amount of data to compensate their development. They also have the opportunity to abound themselves, to stretch to their reach, and determine their potentials and intensify their quality of life. They occupy a world where human warmth, complacency, and confirmation of how remarkable they are, are not met. Many teens feel isolated and unappreciated which most likely increase the 
habit among them to battle in dealing with their curiosities, outrages, or pains. A participant uttered this statement:

"I have so many questions in mind about relationships, love, death, and sex. But I am afraid and shy to ask my parents about these things because I know they are not open about it. That is why I find ways to figure it out..."

The last theme cluster of this foregoing theme is the 'doing the forbidden act'. Most pubescence are inquisitive about sex. A number of them will take interest to find out more. Thus, they will feed their curiosity and experiment. Their engagement to the forbidden act is often based on their impulsivity and immaturity. Their spontaneous behavior and poor decision making prowess most likely led them to break rules. However, their connection to pornographic materials through the television, magazines, and internet makes all the media an avenue for sex. Also, it leads to a very big influence on the lives of the youth. One participant exclaimed this statement with tears on her face: 'It should not happen. I did something not right. Regrets are felt when it's just too late ...'

\section{Bearing a Child}

The Second emergent theme is entitled "Pregnancy: The Child Bearing." Pregnancy is the span of time in women's life from conception to giving birth. It goes through several processes like the union of the sperm and the egg cells, its implantation in the uterus, the long stage of fetal development, and until the delivery of the baby. Such events are also accompanied by physiological and psychological changes in the pregnant mother (Ricci, 2007).

McCall et al. (2015) points out the evident association between deprivation and teenage pregnancy. Socioeconomic values are highly correlated with its occurrence. Minnis et al. (2013) sees that 'limited socioeconomic opportunities may play a large role in persistently high pregnancy rates among Latina adolescents'. In terms of family background, East, Reyes and Horn (2007) concluded that there is more significant likeliness for young women, who had either sister or sister and mother having experienced teenage pregnancy, to yield into the same experience than those young women who had neither sister nor mother experiencing the same. However, under this emergent theme were four cluster themes/contextual categories, namely: a) Teenage Pregnancy, b) Parents know best, c) Education is the key, and d) Ifs and Buts.

The first cluster theme is Teenage Pregnancy. Unlike any other ordinary occurrence of pregnancy, teenage cases are considered the most social concern. It includes pregnancy under the age of twenty at the time the pregnancy terminates. The World Health Organization accounts 16 million 
of birth rate per year that is among women 15-19 year old alone. In the global scale, it accounts for $11 \%$ of all births. Most of which happens among women belonging to low and middle-income countries.

Consequently, the worldview about teenage pregnancy encompasses its usual medical and social implications as far as the health of the young mother and child is concerned (Mukhopadhyay, Chauduri \& Paul, 2010). Unfavorable perinatal outcomes for the mother and the baby remain a priority basis for action (WHO). It also accounts for unsafe abortions among 15-19 years old mothers; maternal deaths among under-sixteens; incidence of anemia, malaria, HIV and other sexually transmitted infections; postpartum hemorrhage; and depression. Machiura (1997) cited several factors related to various reactions to pregnancy, continuing the pregnancy, and the family's reactions to pregnancy such as: timing of pregnancy, legitimacy of a child, financial situation, and women's roles. As described by the participants:

"I don't know what to do when I found out I am pregnant. I know that my parents will disown me. I am afraid and don't want to go home but I really don't know what to do."

However, such reaction to pregnancy can be seen with anxiety related to parental disapproval and/or reprimand. As such, this leads to the feeling of confusion toward responding to what is at hand. Family approval, according to Machiura (1997), is one of the decision reference of the teenage mothers on how to go about their pregnancy. Mann, Cardona \& Gomez (2015) also identify the feeling of shock upon finding and confirming the pregnancy before attaining its acceptance. Messages from their own parents, family members, and partners are seen as the directive towards the resolution of it.

Parents serve many essential roles toward their children leading to the second theme cluster called 'parents know best'. According to American College of Pediatricians (2013), "parents provide the foundational role of support, nurturance, and guidance for their children." Such role of the parents toward their children is seen as a fundamental right of the children in the society. This right is directed towards their welfare, and so that they might be protected from different abuses. In preventing teenage pregnancy, parents should observe different measures in providing guidance and directions to their adolescent children.

On the matter of teenage pregnancy in the family, the same roles was expected and observed from the parents of the teenage mothers. Huge part of the parental guidance for the adolescents were indicated on the prevention of premarital/teen/unwanted pregnancy. Thus, this is viewed by parents as precursor to long term negative outcome which affects the young women most especially (Kim, 2008). One informant of this study stated: 
"It was late when I realized that my parents were right. If I just listened to them, I will not have an early pregnancy. I might finish my schooling then. I viewed them as my antagonists."

Arceo-Gomes, Campos-Vasquez and Raymundo (2014) specified some of the effects of teenage pregnancy such as: decrease of 0.6-0.8 years of schooling, lower attendance, fewer hours of work, and a higher marriage rate. This result doesn't end here. In fact, it results to a 1-1.2 years loss in education and a lower household income per capita. Subsequently, such outcomes seem to have been like prior knowledge or forecast of the parents when their teens falls into dangerous sexual activity. Hence, their opposition in engaging in teen sexual acts is very firm.

However, even after pregnancy has taken its toll in the young mothers, parents still continue their roles in guiding and supporting their children who are turning into parents. Furthermore, parents are one of the support network and coaches in resolving pregnancies (Mann, Cardona \& Gomez, 2015). Anwar and Stanistreet (2015) seconded it by stating that young mothers rely too much on the people who are always at their back such as their family, trusted friends, and other people who they believe could be of help to them. Therefore, this is one of the primary reason how the apparently challenging and anxiety-inducing instance becomes a positive experience.

Kim (2008) indicated that parental influence is an integral force in preventing teenage pregnancy. Several themes which were found across various literatures include the following: (1) The intact family structure is associated with delayed and reduced levels of teen sexual activity and reduced risk of teen pregnancy, (2) Parental disapproval of teen sex, specifically teens' perceptions of their mothers' disapproval, is linked to delayed sexual activity and reduced risk of teen pregnancy, (3) Higher levels of parent-teen relationship satisfaction and a strong connection between teens and their mothers are associated with delayed sexual initiation. (4) Greater parental monitoring and rules which appears to be correlated with reduced teen sexual activity, though the evidence is mixed, and (5) The evidence on parent-child communication, in general or specifically about sexual issues, is mixed. Here, the relationship may vary by the content and the degree of discussion as well as other factors.

Therefore, these show that the following are crucial: the intact family structure, parental disapproval of teen sex, parent-teen relationship satisfaction, and a greater parental monitoring in reducing the incidence of teenage pregnancy.

Based on the National Campaign to Prevent Teen Pregnancy as cited by the Ohioline, there are ten tips for children to avoid teen pregnancy. These tips are as follows: a) Be clear about your own values and attitudes; b) 
Talk with your children early and often and be specific; c) Establish rules, curfews, and expectations of behavior; d) Know your youth's friends and their families; e) Encourage group activities and limit one-on-one dating at an early age; f) Set limits of two- or three-year age difference while your child is a teen; g) Talk with your teenager about the goals for the future; $h$ ) Encourage high and achievable expectations for school performance; i) Know what your teen is watching, reading, and listening to; j) Strive for a positive relationship with your teen.

'Education is the key' is the third cluster theme, which gives reference to the role of sexuality education programs in rendering helpful knowledge and attitude towards human development, heterosexuality, relationships, gender roles, and decision-making on their sexuality. Sexuality education is deemed to be one of the potential factors that can address the issue of teenage pregnancy (Ochiogu et al., 2011). Frost and Forest (1995) cited that the integration of sexuality education in the curriculum provides a broad and rich channel of information about "a variety of sexuality-related issues, from the growth and development of the human body and reproductive physiology to the development of healthy sexual attitudes and values." As cited by one of the participants:

"Sex education plays a big role for us youth, so that we will be prevented to do things that could put us in danger. It should be compulsory in the schools."

It can be seen from the above statement how the informant sees sexuality education as something important in the preventive levels of the issue. The provision of this education in schools is regarded to be highly valuable. Many authors agree on the greater effectiveness of comprehensive sexuality education compared to abstinence-only education. This would assist in delaying sexual activity, increasing safer sexuality behaviors (contraceptive use), having fewer sexual partners, and reduced frequency of sexuality. These all contributes to lower rates of teenage pregnancy and sexually transmitted infection contractions (Advocates for Youth, 2013; Stanger-Hall \& Hall, 2011; Williams, 2011; Dyson \& Mitchell, 2005). Ochiogu et al. (2011) further suggests that such teaching about sexuality for the teens should commence earlier than the junior secondary school, before 14 years old for maximum impact. It goes with the recommendation cited by Dyson and Mitchell (2005) that school-based education serves as the most efficient way of educating the adolescents before they become sexually active.

Logical solution was asserted by Frost and Forest (1995). This was despite many failures of various teenage pregnancy prevention programs. In their study, they claimed that decreasing the number of sexually active teenagers and providing knowledge about contraceptives to those sexually 
active ones would mitigate the incidence of teenage pregnancy and giving birth. On the contrary, Benton, Robert and Lewis (2011) found out that there were no significant changes in youths' forecasts regarding sexual debut in either groups under abstinence-only program or service learning curriculum. Amu and Appiah (2006) opines that various attempts to resolve such unwanted pregnancy does not fit the huge hole of the problem. They specify that in spite of giving information about the use of contraceptives, its inconsistent use by the teenage people defeats all its premeditated purpose. As a result, such provision to emergency contraception only depreciates the value of commitment in relationships.

The last theme cluster is 'ifs and buts'. However, approaching adulthood without committing the so-called "unwanted" and "premarital" pregnancy has been the norms of the society. It does ideally operate this way as the other way around bears serious repercussions on the welfare of the young mothers most especially. Teen sexual activity is usually associated with negative outcomes that bear long term "physical, emotional, social, and economic impacts on the lives of young people, but much more for the young women. (Kim, 2008)"

Mangino (2008) identified that teenager mothers drop out from school to give way to assume their mothering role. Among the young mothers and fathers, the former suffers the consequences the most which include: impediment in education, the health risks for the mother, developmental crisis, and family constraints. SmithBattle (1992) identified, from the most disadvantaged teenage young mothers, the feeling of wanting to be off the road of desolation in the future where the fulfilment of their roles is anticipated to become tough and struggling.

Consequently, the attitude towards teenage pregnancy is marked with ambivalence from the standpoint of the adolescents (Grace, Ihuoma \& Temitope, 2013). As described by one of the participants:

"I am now 18 and have an 11 month old boy. I have never regretted anything. Don't get me wrong it was a shock at first when I found out, I was scared and started thinking about all the things I can never do and like you say I thought I would miss the freedom, however saying that as soon as I had him and I looked at him all thoughts went out the window and that was it, I know what I wanted and what I was meant to do with my life..."

Spear (2004) identified one theme labeled as "regrets and hopes for a better future". It refers to "a sense of loss and feelings of isolation" toneddown with being hopeful for a better future. One of the informants in this study spoke about the feeling of being alone, expecting the partner's and his family's support but to no avail. Eventually, it led her to the feelings of regret. However, capitalizing on her own family support, she made her way 
to the top of the situation to have a better future. Another case regrets was that she should have been married first before having the pregnancy. Young mothers express their general satisfaction on their condition and admitted that some changes in their attitudes arouse as they step into the actual motherhood. Teenage pregnancy/motherhood can be a positive and even rational event (Arai, 2009).

\section{The Mother and Child}

Motherhood is a phenomenon and/or occurrence of having and/or rearing an offspring. It is a feeling similar to the kaleidoscope of various emotions such as fear, excitement, worry, angst, and pride happening at the same time. To copiously divulge the essence of this emergent theme, theme clusters were formulated from the narratives such as (1) state of ambivalence, (2) suffering of a teenage mom and baby, (3) mama versus marriage, and (4) still alive and kicking. Therefore, each of the theme clusters will be further discussed in lieu with an ample description of the participants’ narration.

State of ambivalence is the first theme cluster emerged from the foregoing emergent theme. Ambivalence is well expressed as the experience of having a both positive and negative feeling concerning something. Teen mothers are often perceived as having inadequate coping skills and social support. Ambivalence progresses from worries regarding the capability in the provision of well sufficient mothering to their offspring's such as to be properly alert, adequately attuned, and nurturing enough to attain the continuing essentials necessity. The literature proposes that a delicate balance must be in place for a teen /young mothers. Thus, this would help them to have the satisfactory encouragements and provisions they need to be a good parent. Barnes mentioned that 'Assisting women throughout gestation till post partum period is indeed beneficial to them to gain emotional access to some of the negative and confusing beliefs that influence their behavior, cognitions, and feelings to minimize the potential risk for a postpartum depression. Furthermore, it can boost the growing attachment between mother and infant thereby securing a more positive outcome for the psychological development of the child' (2013). During the interviews, teen mothers were jammed amongst these distinct emotions in child rearing .One of the participants spoke about the state of ambivalence she experienced as a teenage mother:

'I am happy, however, I am afraid because I don't know how to be a mother, I don't know how to stop the baby when he is crying.'

Motherhood is the foremost reason teenagers quit schooling. Furthermore, fathers neither marry them nor help them in raising the child, 
but usually leaves the sole responsibility to them. This truth leads to the second theme cluster called 'the agony of a teenage mom'. A study conducted by Hanna (2001) revealed that issues such as immaturity, untrained to motherhood, and dependency were amongst the hard struggles faced by sole - supporting mothers during their teenage years. Moreover, the stigma they were confronted with in their community includes the visit they had in their community health centers. Throughout the conversations made with the participants, they had conveyed several concern. Among the major troubles teenage mothers had was in not having a job to buy the necessities needed for caring for their offspring. In an event they do, teen moms typically work few hours because of school and /or the sad part is in quitting schooling to find work and earn some money. During their pregnancy, teen mothers usually cannot afford doctor visits, vitamins, ultrasounds, etc. and others aspect which is essential for prenatal care. They only recourse to avail the public/government/NGO assistance or, often than not, were covered by their parents. However, one participant uttered her experience about the Agony of a Teenage Mommy.

'I don't know how to finance my baby's milk. It's always been my mom and dad who shoulder everything. I am ashamed of what's happening'

The third theme cluster is 'baby mama versus marriage'. The term "Baby Mama" refers to an unmarried young woman. Teen marriage is normally regarded as the union of two people, either one or both of their ages ranges between 13 to 19 years old (Teenager/Adolescence). According to study, 8 out of 10 teenager fathers don't marry the mother, talk less of helping them in rearing the child. Subsequently, some studies posited that many young married couples who originated from broken homes, little education, and who were working in low status occupations were often less beneficial than those that got married after adolescence (Kiernan \& Kathleen E, 1986). Several participants conveyed that the reason they do not compel themselves to get married is because they felt that they are too juvenile; not physically, mentally, emotionally and financially prepared; and likewise, parents of both parties do not agree on the aforementioned undertakings. One of the participants uttered in a low toned voice that.

'It was the consensus of everyone not to tie the knot because we are too young, physically, mentally, emotionally and financially unstable, besides both of our parents suggested this set up.'

Despite what happened, teenage mothers are ready to face all the challenges of rearing their offspring. Thus, this leads to the fourth and last emergent theme, still alive and kicking. They believe that everything happens for a reason. They continue fighting and proving that it is not too late to 
make their lives better. One of the participants confidently uttered, ' $I$ know I will get through all of these. I will be fine and my baby will be okay too.'

\section{Building New Dreams}

The last theme that emerged from the lived experiences conveys the future that awaits the chosen participants of the study. All of their experiences, no matter how simple or complicated they were, imparted them with lessons. This lessons either construct or destroy them to endure facing life's confronts. Four cluster themes were engendered from this emergent theme, which emulates the experiences of the teenage mothers: picking up the broken pieces; starting up... a new life; love, courage, and hope; and tomorrow's plan. As discussed in the previous emergent themes, teenage pregnancy had huge impacts not only to the child bearer, but as well their families and friends. Simmons (2006) mentioned in her study that majority of the teenagers who got pregnant do not engaged in marriage due to physical, psychological, and financial instability. However, some of the participants' verbalized that the effects of teenage pregnancy were life changing. These changes shuttered their dreams and aspirations to have better lives adding to the burden of the discrimination and stereotyping of people towards this worldwide social phenomenon. To better understand this foregoing theme, three theme clusters were drawn.

The first theme cluster derived from the foregoing emergent theme focuses on building the lost identity of the teenage mothers during the pregnancy period and after delivery. This theme cluster is named 'picking up the broken pieces'. All of the participants expressed their desire to start where they fall. Some of the participants are planning to go back to school; others have already decided to finally focus on being full-time mothers; and the latter consider getting married soon. Despite series of unfortunate events in their lives, teenage mothers are willing to pick up the broken pieces they once left.

The second theme cluster is 'starting up a new life'. As teen mothers learned more about themselves and honored the path that called them, they become stronger. All of the participants would like to start anew, no matter what people would tell them. Therefore, they are willing to work harder to provide a good life for their children.

The last theme is called 'tomorrow's plan'. All of the teenage mothers believed that their children would continue their lost dreams. Also, what they had experienced in life would be their guiding principles in raising their children. Even though they have learned the lessons of life the hard way, they are still thankful and hopeful about the life that awaits them. In spite of everything, they are still willing to continue the dream they once left behind. 
"We are okay now. I have already adjusted and I am ready now to be a mother to my baby and my soon to be babies. Thanks to all the people who supported and loved me. Now, I know the ABC's of Motherhood. "

\begin{tabular}{|c|c|c|c|c|}
\hline Essence & \multicolumn{4}{|c|}{ Education } \\
\hline Emergent Themes & $\begin{array}{c}\text { Period of } \\
\text { Adolescence }\end{array}$ & Child Bearing & $\begin{array}{c}\text { Mother and } \\
\text { Child }\end{array}$ & $\begin{array}{c}\text { Building New } \\
\text { Dreams }\end{array}$ \\
\hline Theme Clusters & $\begin{array}{c}\text { Metamorphosis } \\
\text { of a Girl to a } \\
\text { Lady }\end{array}$ & $\begin{array}{c}\text { Teenage } \\
\text { Pregnancy }\end{array}$ & $\begin{array}{c}\text { State of } \\
\text { Ambivalence }\end{array}$ & $\begin{array}{c}\text { Picking Up the } \\
\text { Broken Pieces }\end{array}$ \\
& $\begin{array}{c}\text { Teenage } \\
\text { Dilemma }\end{array}$ & $\begin{array}{c}\text { Parents Know } \\
\text { Best }\end{array}$ & $\begin{array}{c}\text { Suffering of a } \\
\text { Teenage Mom }\end{array}$ & $\begin{array}{c}\text { Starting Up a } \\
\text { New Life }\end{array}$ \\
& $\begin{array}{c}\text { Exploring the } \\
\text { Curious Mind }\end{array}$ & $\begin{array}{c}\text { Education is the } \\
\text { Key }\end{array}$ & $\begin{array}{c}\text { Baby Mama } \\
\text { Versus Marriage }\end{array}$ & $\begin{array}{c}\text { Tomorrow's } \\
\text { Plan }\end{array}$ \\
& Doing the & Ifs and Buts & Still Alive and \\
Kicking & \\
& Forbidden Act & & & \\
& & & &
\end{tabular}

Table 1. Matrix of the Lived Experiences of Teenage Mothers

\section{Discussion}

All of the emergent themes reflected the lived experiences of the participants in their teenage pregnancy and motherhood journeys. The first theme, awakening: the period of adolescence', depicted the growth and development of a girl to a lady. It also showed how teenagers struggled about their bodily changes and how they can fit into the society. Peer pressure is one of the major challenges at this point. Proper guidance from the parents and family members should be offered to teenagers not to feel being left behind. Sex education in the school should already have been initiated to keep away teenagers from discovering it by themselves. By knowing the effects and disadvantages of teenage pregnancy and early parenthood, this would teach them to become a responsible person. Therefore, educating teenagers is still the best way to prevent teenage pregnancy.

The second theme, 'pregnancy bearing a child', showed the challenges and struggles of conceiving a child. It illustrated how a teenager behaves and responds to her present condition. Early pre-natal check-ups should be initiated at this stage to ensure that the baby will be delivered healthy and safely. The role of parents, especially the mothers, are crucial at this point. Pregnant teenagers have little knowledge about child-bearing. Technically, she will be depending on her mother for all the information she 
needs to know in taking care of her baby. Other support groups are highlyencouraged to motivate the teenager to accept her situation wholeheartedly.

Motherhood: The Mother and the Child is the third theme that emerged from the lived experiences of the participants. This theme depicted the teenager's new role - as a mother. Motherhood is said to be the hardest thing that a woman could experience in her life. Teenagers have no enough experience to take care of a child and, at the same time, provide the needs of her child. Parents will be the provider of the entire mother and child's need. Nowadays 'forced marriage' is not an option anymore. Parents of both parties may either have settlement regarding the visitations, financial arrangements, and other conditions both agreed upon considering that both parties are still on minor age (less than 18 years old). At this point, teenagers may choose whether to continue or end their relationships. Some teenage couples end up together until the time they can establish a family of their own. However, majority of them decided to continue life without the company of each other.

The last emergent theme is 'futurity: building new dreams'. This theme described the faith, hope, and love of the teenage mothers to continue their lives in spite of the challenges they have experienced. Here, the teenage mothers began to build new dreams for themselves and their families. They are now stronger, more empowered, and wiser this time. All of them are convinced that everything happens for a reason. Through all the ups and down in their lives, they still managed to adjust, adapt, and cope. Therefore, all of them are ready to face the next chapters of their lives.

\section{Conclusion}

The over-all proposition of the study evolves with the essence of 'health education'. This serves as an 'eye opener' to individuals to get involve in the public awareness, planning, implementation, and evaluation of the programs that would build sustainable development. Active involvement is a pre-requisite to success. As early as possible, sex education should be incorporated in the curriculum of the intermediate and secondary school to properly educate them on the effects and disadvantages of early pregnancy.

\section{Implication for Practice}

This study recommends promotion of sex education as early as possible to prevent the detrimental effects of teenage pregnancy. Educational facility and parents should work hand-in-hand in building activities and programs that would provide sufficient knowledge for children and teenagers not to engage in activities inappropriate for their ages like sexual intercourses. Responsible parenthood is a major key to prevent teenage pregnancy. Moreover, technological advancement should be strictly limited 
to minor age or less than 18. Social networking sites should be strict in implementing these rules especially where online sites nowadays are now the express ticket in meeting people regardless of their age and gender. Lastly, future research pertaining the topic is highly encouraged.

\section{Funding}

The authors received no financial aid or support for the research, authorship, and/or publication of this article.

\section{References:}

1. Abu Sosha, G. (2012). Employment of Collaizi’s Strategies in Descriptive Phenomenology: A Reflection of a Researcher. European Scientific Journal. November Edition, Vol. 8, No. 27. ISSN: 18577881 (Print) e-ISSN 1857-7431.

2. Advocates for Youth (2013). available at: www.advocatesforyouth.org (accessed October 24, 2014).

3. American College of Pediatricians (2013). The Roles, Responsibilities and Rights of Parents. Retrieved at: https://www.acpeds.org/the-college-speaks/positionstatements/parenting-issues/the-roles-responsibilities-and-rights-ofparents

4. Amoran, E. (2012). A comparative analysis of predictors of teenage pregnancy and its prevention in a rural town in Western Nigeria. International Journal for Equity in Health, 11:37. http://www.equityhealthj.com/content/11/1/37

5. Amu, O., \& Appiah, K. (2006). Teenage pregnancy in the united kingdom: Are we doing enough? European Journal of Contraception \& Reproductive Health Care,11(4), 314-8. Retrieved from

6. Andrews H \& Roy C. (1991). The Adaptation Model. Norwalk: Appleton and Lange.

7. Anwar, E., \& Stanistreet, D. (2015). 'It has not ruined my life; it has made my life better': A qualitative investigation of the experiences and future aspirations of young mothers from the north west of england. Journal of Public Health (Oxford, England), 37(2), 269276. doi:http://dx.doi.org/10.1093/pubmed/fdu045

8. Arai, L. (2009). What a difference a decade makes: Rethinking teenage pregnancy as a problem. Social Policy and Society, 8(2), 171-183. doi:http://dx.doi.org/10.1017/S1474746408004703

9. Arceo-Gomez, E., \& Campos-Vazquez, R. (2014). TEENAGE PREGNANCY IN MEXICO: EVOLUTION AND CONSEQUENCES*. Latin American Journal of Economics,51(1), 109-146. 
10. Benton, A. D., Roberts-gray, C., \& Lewis, C. M. (2011). Abstinencebased versus service learning prevention education in small groups: Effects on the life plans of young adolescents. Child \& Adolescent Social Work Journal, 28(1), 23-34. doi:http://dx.doi.org/10.1007/s10560-010-0216-7

11. Bryman A. (2012). Social Research Methods (4th ed.) New York: Oxford University Press.

12. Collaizi PF. (1978). Psychological research as the Phenomenologist Views it. In R.S. Valle and M. King (eds.). Existential Phenomenological Alternatives for Psychology (pp. 48-71). New York: Oxford University Press.

13. Collaizi PF. (1978). Learning and Existence. In R.S. Valle and M. King (eds.). Existential Phenomenological Alternatives for Psychology (pp. 119-135). New York: Oxford University Press.

14. Crano, Prislin, William D., \& Radmila (2011). Attitudes and Attitude Change. Psychology Press. pp. 262-285

15. Creswell JW. (2009). Research Design: Qualitative and Mixed Methods Approaches. London: SAGE.

16. Crotty M. (1989). The Foundations of Social Research. London: SAGE.

17. Dulitha, F., Nalika, G., Upul, S. Christantha \& De Alwis, S. (2013). Risk factors for teenage pregnancies in Sri Lanka: perspective of a community based study. Health Science Journal, 7.3, pp. 269-284.

18. Dyson, S., \& Mitchell, A. (2005). Sex education and unintended pregnancy: Are we seeing the results? Australian Health Review, 29(2), 135-9. Retrieved from

19. East, P. L., Reyes, B. T., \& Horn, E. J. (2007). Association between adolescent pregnancy and a family history of teenage births. Perspectives on Sexual and Reproductive Health, 39(2), 10815.

20. Eloundou-Enyegue, P. (2004). Pregnancy-Related Dropouts And Gender Inequality In Education: A Life-Table Approach And Application To Cameroon. Demography (pre-2011), 41, 3, pp. 509528.

21. Frost, J. J., \& Forrest, J. D. (1995). Understanding the impact of effective teenage pregnancy prevention programs. Family Planning Perspectives, 27(5), $188 . \quad$ Retrieved from http://search.proquest.com/docview/224555941?accountid=38643

22. Grace, A. R., Ihuoma, I. H., \& Temitope, N. R. (2013). Attitude and perception of adolescents towards teenage pregnancy in makurdi metropolis. Gender \& Behaviour, 11(1), 5272-5277. 
23. Hanna, B. (2001, May 21). Negotiating motherhood: The struggles of teenage mothers. Retrieved June 13, 2016, from http://www.ncbi.nlm.nih.gov/pubmed/11380712.

24. Kiernan \& Kathleen E. (1986, March 1). Teenage Marriage and Marital Breakdown: A Longitudinal Study.

25. Kim, C. (2008). Teen Sex: Parent Factor. Retrieved at: http://www.heritage.org/ research/reports/2008/10/teen-sex-theparent-factor.

26. Machiura, M. (1997). Experiences of pregnancy among japanese teenagers: Decisions and perceptions of being a pregnant teenager (Order No. 9738373). Available from Nursing \& Allied Health Database. (304363727). Retrieved from http://search.proquest.com/docview/304363727?accountid=38643.

27. Mangino, J. G. (2008). Voices of teen mothers: Their challenges, support systems, and successes (Order No. 3322340). Available from Education Database. (220006032).

28. Mann, E. S., Cardona, V., \& Gómez, C.,A. (2015). Beyond the discourse of reproductive choice: Narratives of pregnancy resolution among Latina/o teenage parents. Culture, Health \& Sexuality, 17(9), 1090-1104. doi:http://dx.doi.org/10.1080/13691058.2015.1038853.

29. McCall, S. J., Bhattacharya, S., Okpo, E., \& Macfarlane, G. J. (2015). Evaluating the social determinants of teenage pregnancy: A temporal analysis using a UK obstetric database from 1950 to 2010. Journal of Epidemiology and Community Health, 69(1), 49. doi:http://dx.doi.org/10.1136/jech-2014-204214.

30. Minnis, A. M., Marchi, K., Ralph, L., Biggs, M. A., Combellick, S., Arons, A., . . . Braveman, P. (2013). Limited socioeconomic opportunities and latina teen childbearing: A qualitative study of family and structural factors affecting future expectations. Journal of Immigrant and Minority Health, 15(2), 334-40. doi:http://dx.doi.org/10.1007/s10903-012-9653-z.

31. Mukhopadhyay, P., Chaudhuri, R. N., \& Paul, B. (2010). Hospitalbased perinatal outcomes and complications in teenage pregnancy in india. Journal of Health, Population and Nutrition, 28(5), 494-500.

32. Ochiogu, I. N., Miettola, J., Ilika, A. L., \& Vaskilampi, T. (2011). Impact of timing of sex education on teenage pregnancy in nigeria: Cross-sectional survey of secondary school students. Journal of Community Health, 36(3), $375-80$. doi:http://dx.doi.org/10.1007/s10900-010-9318-6

33. Ohioline. Parental involvement can reduce the risk of teenage pregnancy. Ohio State University Extension. Retrieved at: http://ohioline.osu.edu/factsheet/FLM-FS-16-99-R10 
34. Patra, S. (2016). Motherhood in childhood: addressing reproductive health hazards among adolescent married women in India. Reproductive Health, 16.

35. Philippine News Agency (2012). Teenage pregnancies in Philippines rise 70-percent over 10 years - UNFPA. Interaksyon. http://www.interaksyon.com/article/30434/teenage-pregnancies-inphilippines-rise-70-percent-over-10-years---unfpa

36. Raj, A., Rabi, B., Amudha, P., van Teijlingen, E. \& Glyn, C. (2010). Factors associated with teenage pregnancy in South Asia: a systematic review. Health Science Journal, 4, 1, pp. 3-13.

37. Ricci, S. (2007). Essentials of Maternity, Newborn, and Women's Health Nursing. Lippincott Williams \& Wilkins. Philadelphia PA 19106

38. Roy C. (1980). The Roy Adaptation Model. In Riehl, J. P.; Roy, C. Conceptual Model for Nursing Practice. Norwalk: Appleton: Century Crofts.

39. Salvador, J. T. (2016). Exploring Quantitative and Qualitative Methodologies: A Guide to Novice Nursing Researchers. European Scientific Journal, 12(18).

40. Seamark, C. (2001). Design or accident? The natural history of teenage pregnancy. Royal Society of Medicine (Great Britain). Journal of the Royal Society of Medicine, 94, 6, pp. 282-285.

41. SmithBattle, L. (1992). Caring for teenage mothers and their children: Narratives of self and ethics of intergenerational caregiving (Order No. 9303555). Available from Nursing \& Allied Health Database. (304015355). Retrieved from http://search.proquest.com/docview/304015355?accountid=38643

42. Spear, H. J. (2004). A follow-up case study on teenage pregnancy: "havin' a baby isn't a nightmare, but it's really hard". Pediatric Nursing, 30(2), 120-5.

43. Stanger-Hall, K., \& Hall, D. W. (2011). Abstinence-only education and teen pregnancy rates: Why we need comprehensive sex education in the U.S. PLoS One, 6(10) doi:http://dx.doi.org/10.1371/journal.pone.0024658

44. Wall-Wieler, E., Ross, L., \& Nickel, N. (2016). Teenage pregnancy: the impact of maternal adolescent childbearing and older sisters teenage pregnancy on a younger sister. BMC Pregnancy and Childbirth, 16.

45. World Health Organization. Adolescent Pregnancy. Retrieved at: http://www.who.int/ maternal_child_adolescent/topics/maternal/adolescent_pregnancy/en/ 
46. World Health Organization. Maternal, newborn, child and adolescent health. Retrieved at: http://www.who.int/maternal_child_adolescent/topics/maternal/ adolescent_pregnancy/en/

47. Xu-Kuan, C., Shi Wu, W., Fleming, N, Demissie, K. \& Rhoads, G. (2017). Teenage pregnancy and adverse birth outcomes: a large population based retrospective cohort study. International Journey of Epidemiology, 36, 2, pp. 368-373. 